\title{
Effect of a New Natural Seasoning on the Formation of Pyrazines in Barbecued Beef Patties
}

\author{
Javier García-Lomillo, Ma Luisa González-SanJosé, Raquel Del Pino-García, \\ Miriam Ortega-Heras, and Pilar Muñiz-Rodríguez \\ Department of Biotechnology and Food Science, Faculty of Science, University of Burgos, Plaza Misael Bañuelos, 09001 Burgos, Spain \\ Correspondence should be addressed to Ma Luisa González-SanJosé; marglez@ubu.es
}

Received 30 December 2015; Revised 15 April 2016; Accepted 13 June 2016

Academic Editor: Paula G. De Pinho

Copyright (c) 2016 Javier García-Lomillo et al. This is an open access article distributed under the Creative Commons Attribution License, which permits unrestricted use, distribution, and reproduction in any medium, provided the original work is properly cited.

\begin{abstract}
The formation of pyrazines in food cooking is required to obtain satisfactory "roasted" flavor. The aim of this work was to evaluate the effect of a new red wine pomace seasoning (RWPS) on the formation of pyrazines in barbecued beef patties. Five pyrazines were successfully identified, 2,5-dimethylpyrazine being the most abundant. Although 2-ethyl-5-methylpyrazine was in lower levels, it presented the highest odor units, due to its low threshold. RWPS enhanced the formation of the five identified pyrazines (2.1 times), without relevant changes in the proportion between them. The highest increase was observed for 2-ethyl-6-methylpyrazine (3 times higher than in control). These results were corroborated by electronic nose analysis, presenting RWPS beef patties higher odor intensities. Mechanisms to explain these effects are also proposed in the present work, and the high content of polyphenols seems to be the major cause of the observed results. The use of RWPS could improve the flavor characteristics of meat products or enable using less intense cooking conditions with no changes in the flavor.
\end{abstract}

\section{Introduction}

Pyrazines are a class of heterocyclic compounds with two nitrogen atoms in para position with a major role in the "roast" flavor of foods. In this sense, pyrazines present a large impact on the flavor of cooked meat products, accounting for up to $80 \%$ of total volatiles [1]. Currently, pyrazines are included in the list of flavoring agents authorized by the European Union and are incorporated by the food industry to imitate meat flavors. Although some studies reported certain mutagenic activity of pyrazines [2], the concentration required is several orders of magnitudes higher than the normal intakes in Europe [3].

The formation of pyrazines has been reported in frying and roasting, but not in boiled meat products [4]. They are usually present in those products elaborated at high temperatures. Their odor threshold values are low and the most common associated odor notes are roasted nuts, coffee, and chocolate flavors (Table 1) [5-7]. Due to the fact that the formation of pyrazines is required to achieve an optima sensory quality of roasted meat products, different research works have been conducted in order to ensure an adequate formation of this type of compounds and to optimize their final concentration [8, 9]. Many factors may affect the formation of pyrazines, such as temperature and duration of processing, $\mathrm{pH}$, or water content [4], and then several technological factors need to be taken into consideration in order to achieve an adequate level of pyrazines [10, 11]. Furthermore, the ingredients of meat products have to be also considered $[4,6,12]$.

In relation to the ingredients used in the recipes of meat products and according to previous studies, the presence of natural phenolic compounds may inhibit or promote the formation of pyrazines affecting quality of the final product [13-15]. Contradictory effects were exerted by pure phenolics, whereas gallic acid almost completely inhibited pyrazine formation and ellagic acid showed strong promoting activity [14]. Misnawi et al. [13] detected that the increase of polyphenol levels limited the formation of pyrazines in roasting process. The inhibition was different for each pyrazine, 2,3dimethylpyrazine being the most strongly affected. Authors also observed that the presence of polyphenols reduced the 
TABLE 1: Pyrazines commonly found in meat products and their published ${ }^{\mathrm{a}}$ flavor characteristics.

\begin{tabular}{|c|c|c|}
\hline & Structure & Flavors \\
\hline 2,5-Dimethylpyrazine & & $\begin{array}{l}\text { Chocolate, roasted nuts, roasted barley aroma, } \\
\text { chocolate taste, butter odor, fried potatoes. }\end{array}$ \\
\hline 2,6-Dimethylpyrazine & & $\begin{array}{l}\text { Roasted, coffee, nutty, peanuts, chocolate flavor, potato } \\
\text { aroma. }\end{array}$ \\
\hline 2,3-Dimethylpyrazine & & Green nutty, caramel, potato, cocoa, coffee. \\
\hline 2-Ethyl-6-methylpyrazine & & Roast, sweet. \\
\hline 2-Ethyl-5-methylpyrazine & & Nutty, roasted. \\
\hline
\end{tabular}

${ }^{\mathrm{a}}$ References: [5-7].

level of free amino acid and reducing sugar, limiting their participation in the Maillard reaction. However, Wilker et al. [15] observed that pure polyphenols, specially gallic acid, are able to promote the Maillard reaction. This fact was explained by their ferric reducing capacity, inducing Fenton reaction and glucose degradation cyclically. The effect was less pronounced at high levels of polyphenols, which was ascribed to the metal chelation activities of polymerized polyphenols.

Natural products rich in antioxidants also showed different effects, so in the case of grape skin and seed extracts a complete inhibition of the pyrazines formation was described whereas, in contrast, rosemary seasoning enhanced the formation of pyrazines [14].

A considerable amount of literature has been published on the application of the electronic nose to assay the quality of meat products [17] and, according to the review done by Elmore [18], metal oxides sensors have been successfully applied to study the aroma of different cooked meat products and satisfactory correlations with sensory results which have been obtained. From these facts, electronic nose could be a suitable tool to study the odor modification of roasted patties induced by the inhibition or promotion of pyrazine formation.

Recently, new natural seasonings derived from wine pomace have been successfully applied to different food matrices, including beef patties [19]. The seasonings were characterized in terms of main chemical composition, mineral, phenolic composition, radical scavenging, and ferric reducing activities [20, 21]. Then, considering the future applications of these seasonings in meat product recipes, the aim of this study was to evaluate the effect of one of these seasonings on the formation of pyrazines in barbecued beef patties. The seasoning used in the present study was chosen due to its intense antioxidant and preservatives properties.

\section{Material and Methods}

2.1. Materials. Beef meat and salt were purchased in a special grocery wholesale store placed in Burgos (Gros Mercat, Burgos, Spain), and a commercially available mixture of phosphates and starch were provided by Doscadesa (Murcia, Spain). The seasoning derived from red wine pomace (RWPS) was made in the pilot plant of the Food Technology Area (University of Burgos) according to the patented process [22].

2.2. Preparation and Cooking of Samples. Beef patties were prepared according to the process described by GarciaLomillo et al. [19]. Briefly, control patties were prepared from beef meat that was minced and mixed with $1.2 \%$ of starch, $0.3 \%$ of phosphates, and $1.5 \%$ salt previously dissolved in $5 \%$ of water. After mixing, balls of $100 \mathrm{~g}$ of mixed meat were gently handmade and flatten into one $\mathrm{cm}$ thick patties. RWPS patties were made similarly but $2 \%$ of the studied seasoning was added during mixing process. The $\mathrm{pH}$ of raw patties was assessed using a Crison 2001 pH meter (Crison, Barcelona, Spain). 


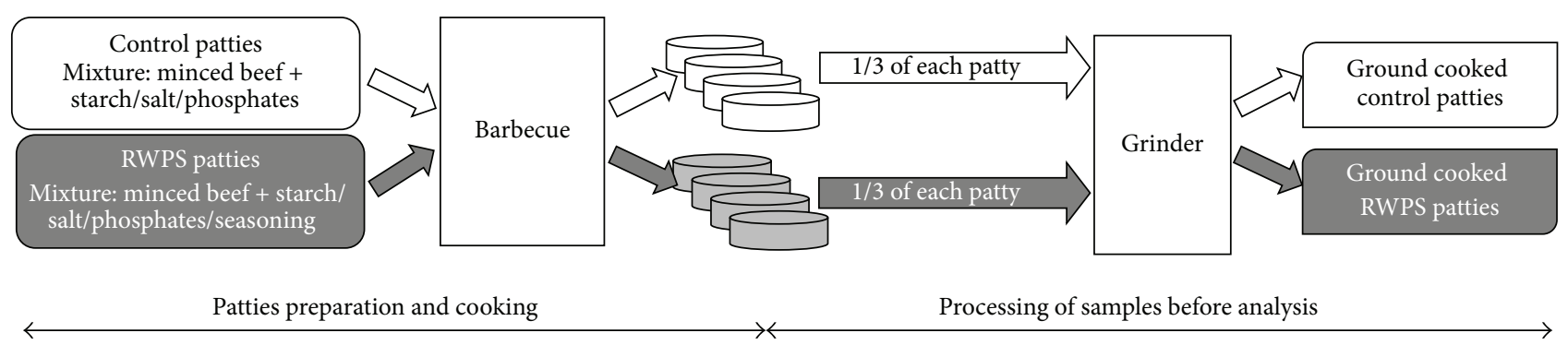

FIGURE 1: Scheme of sampling preparation.

Patties were cooked in a charcoal barbecue, where racks were positioned at $8 \mathrm{~cm}$ of distance from the heat source, where temperatures reached $200 \pm 3^{\circ} \mathrm{C}$. Samples were turned once during grilling at half of the total cooking time (7 minutes). After cooking, patties were immediately cooled, and four patties were preserved to pyrazine analysis (Figure 1).

The assay was carried by duplicate, so two different mixings were made for each type of patty.

2.3. Determination of Pyrazine Contents. Levels of pyrazines were measured directly on ground cooked patties. A third part of four different cooked patties were ground together to obtain a homogeneous mixture of them (Figure 1). Then, two grams of each mixture (control and RWPS patties) was transferred to $10 \mathrm{~mL}$ headspace glass vials (Thermo Scientific $^{\mathrm{TM}}$ Chromacol $^{\mathrm{TM}}$, Barcelona, Spain). Immediately, $5 \mu \mathrm{L}$ of a cyclopentanone: dichloromethane (1:9) solution was added and vials were immediately sealed using a metallic cap with chlorobutyl/PTFE seal (Thermo Scientific ${ }^{\text {TM }}$ Chromacol $\left.^{\mathrm{TM}}\right)$. Cyclopentanone is added as internal standard for gas chromatography-mass spectrometry (GC-MS) analysis. Five vials for each type of patties were prepared. After sealing, vials were analyzed as soon as possible, and they were kept at $4^{\circ} \mathrm{C}$ until analysis. The experiment was repeated with the two different beef meat batches.

Pyrazines were analyzed using a solid-phase dynamic extraction (SPDE) equipment (Bender and Hobein, Zurich, Switzerland) and according to the method developed by Corcuera Tecedor [23]. The extractions were conducted with a previously preconditioned PDMS/AC (90\% polydimethylsiloxane and $10 \%$ activated carbon) fiber at $55^{\circ} \mathrm{C}$. After 50 strokes, the fiber was transferred to the injection port of a GC-MS equipment (Agilent Technologies 6890N). Volatile compounds were thermally desorbed from the fiber in the injection port at $250^{\circ} \mathrm{C}$ and using helium as carrier gas. The separation was conducted in 007-WAX capillary column (Quadrex Corporation, New Haven, USA) (60 m length, $0.32 \mathrm{~mm}$ inside diameter, and $1 \mu \mathrm{m}$ film thickness). Compounds were identified by comparison to the mass spectra of the Wiley 7th and NIST 98 libraries. Standard calibration curves were conducted for quantitative determination. According to the author, calibration curves showed good linearity, repeatability, and recoveries $\left(R^{2}>0.99\right.$; RSD $<$ $10 \%$ and $>95 \%$, resp.) [23]. Moreover, the odor units and the relative odor units were calculated for each pyrazine and each batch according to (1) as described by Lawless and Heymann [24]:

$$
\begin{aligned}
\text { Odor Units }_{a} & =\frac{\text { Concentration }_{a}}{\text { Threshold }_{a}} \\
\text { Relative Odor Units }_{a} & =\left(\frac{\text { Odor Units }}{a}\right) * 100 .
\end{aligned}
$$

2.4. Odor Profile Analyzed by Electronic Nose. Odor profile was also measured directly on grounded cooked patties. After grounding together a third part of each patties, two grams of the grounded mixture was placed in vials, similarly to the described GC-MS analysis, although in this case cyclopentanone was not added.

To determine the odor profile of each type of patties, vials were incubated during 10 minutes at $55^{\circ} \mathrm{C}$ with an autosampler HS100 CTC-Combi-Pal (CTC Analytics AG, Zwingen, Switzerland). Then, a volume of the headspace was injected in a $\alpha$-FOX 4000 electronic nose (AlfaMOS, Toulouse, France) equipped with metal oxide sensors, and the sensor responses were collected during two minutes. The resistance in each sensor was assayed by the software AlphaSoft version 9.1 and the response intensity was calculated as the decrease in the resistance in each sensor $\left(R_{0}-R\right)$ in relation to resistance at time zero $\left(R_{0}\right)$, according to

$$
\text { Response intensity }=\frac{\left(R_{0}-R\right)}{R_{0}} .
$$

The maximum response intensity was used to evaluate the difference in the odor profile between samples with or without seasoning. Samples were analyzed five times for each type of patty and batch.

2.5. Statistical Analysis. Fisher's least significant difference (LSD) test ( $p$ value $<0.05$ ) was performed using Statgraphics Centurion XVI to identify significant differences between the concentrations of each pyrazine of control and RWPS patties and between the sensor responses obtained for each type of patty. Statgraphics Centurion XVI was used to carry out the statistical analysis.

\section{Results and Discussion}

3.1. Effect of the New Seasoning on the Formation of Pyrazines. Different pyrazines, mainly the five indicated in Table 1, have 
TABLE 2: Concentration (mean $\pm \mathrm{SD}$ ) of five pyrazines (ppb) in barbecued beef patties without (control) and with red wine pomace seasoning $(\text { RWPS })^{(\text {a) }}$.

\begin{tabular}{|c|c|c|c|c|c|c|c|}
\hline \multirow{2}{*}{ Pyrazines } & \multirow{2}{*}{ Threshold (ppb) } & \multicolumn{3}{|c|}{ Control } & \multicolumn{3}{|c|}{ RWPS } \\
\hline & & $\begin{array}{c}\text { Mean } \pm \text { SD } \\
(\mathrm{ppb})\end{array}$ & $\begin{array}{l}\text { Odor } \\
\text { units }\end{array}$ & $\begin{array}{c}\text { Relative odor } \\
\text { unit (\%) }\end{array}$ & $\begin{array}{c}\text { Mean } \pm \text { SD } \\
(\mathrm{ppb})\end{array}$ & $\begin{array}{l}\text { Odor } \\
\text { units }\end{array}$ & $\begin{array}{c}\text { Relative odor } \\
\text { unit (\%) }\end{array}$ \\
\hline 2,3-Dimethylpyrazine & 800 & $22 \pm 2^{\mathrm{a}}$ & 0.03 & 0.3 & $53 \pm 4^{\mathrm{b}}$ & 0.07 & 0.3 \\
\hline 2,5-Dimethylpyrazine & 80 & $201 \pm 9^{a}$ & 2.5 & 26 & $394 \pm 63^{\mathrm{b}}$ & 4.9 & 24 \\
\hline 2,6-Dimethylpyrazine & 400 & $164 \pm 19^{\mathrm{a}}$ & 0.4 & 4 & $317 \pm 9^{b}$ & 0.8 & 4 \\
\hline 2-Ethyl-5-methylpyrazine & 16 & $78 \pm 6^{\mathrm{a}}$ & 4.9 & 51 & $160 \pm 15^{\mathrm{b}}$ & 10.0 & 48 \\
\hline 2-Ethyl-6-methylpyrazine & 40 & $70 \pm 4^{\mathrm{a}}$ & 1.8 & 19 & $201 \pm 19^{b}$ & 5.0 & 24 \\
\hline Sum of pyrazines & & $535 \pm 40^{\mathrm{a}}$ & 9.6 & & $1123 \pm 120^{\mathrm{b}}$ & 20.8 & \\
\hline
\end{tabular}

${ }^{(a)}$ Different letters $(a-b)$ denote significant differences (LSD test and $\left.p<0.05\right)$ between samples. Values are means \pm standard deviation of four replicate determinations in two different batches ( $n=10 ; 2$ batches $\times 5$ replicates by sample).

been previously described in diverse cooked meat products [ 1 , 25]. These five commonly described pyrazines were identified and successfully quantified in both control and RWPS patties (Table 2). The global level of dimethyl pyrazines (around 72\%) was higher than ethyl-methyl pyrazines. Two of the three identified dimethyl pyrazines (2,5-dimethylpyrazine and 2,6dimethylpyrazine) showed the highest levels, while the third (2,3-dimethylpyrazine) showed the lowest level, in both types of patties. These observations are in agreement with previous studies that indicate the high prevalence of 2,5- and 2,6dimethylpyrazine $[1,25]$.

The use of the new seasoning significantly enhanced the formation of the five identified pyrazines (Table 2). The sum of all pyrazines was 2.1 times higher in RWPS patties than in control patties. Dimethyl pyrazines increased around 2 times and ethyl-methyl pyrazines increased around 2.5 times. The highest increase was observed in 2-ethyl-6-methylpyrazine, whose concentration was almost 3 times higher in RWPS patties than in control patties.

Generally, the formation of pyrazines is desired in the food processing since it improves the overall sensory preference with low risk of unpleasant attributes caused by excessive pyrazine formation $[4,5,26]$. According to the direct correlation of pyrazines with the "roasted" flavor, which is highly appreciated for consumers [26], it seems possible to assert that the new seasoning produced an interesting enhancement of roasted odor notes. This assertion is supported by the detected levels of pyrazines as well as by the obtained values of odor units for each pyrazine (Table 2).

It is accepted that volatile compounds are perceived when their concentrations are superior to their threshold or in other words when the odor units are equal or superior to 1 . Then, at least three of the five pyrazines analyzed showed enough concentration to be perceived. Dimethyl pyrazines have higher threshold than ethyl-methyl pyrazines and for that reason, although they were predominant in concentration (72\%), they had minor contribution to the global odor units (around 30\%). According to the low threshold value of 2ethyl-5-methylpyrazine, it showed the major potential to contribute to roasted odor note, which was associated with the highest odor unit in both samples (4.9 and 10.0 in control and RWPS patties, resp.) (Table 2). Furthermore, 2ethyl-5-methylpyrazine presented the highest relative odor unit, approximately $50 \%$, in both types of patties (Table 2), suggesting its major role in the "roasted" odor notes.

It is interesting to point out that the odor intensity was increased by the incorporation of the seasoning. Patties elaborated with the seasoning showed higher values of odor units than control patties (around 2.2 times higher), the odor units of the ethyl-methyl pyrazines being those that presented a more intense increase. So, the relative odor of these two pyrazines was slightly higher in RPWS patties (72\%) than in control (70\%).

Considering these facts and as a preliminary approximation of the possible sensory response, the "odor profile" of patties was analyzed by an e-nose equipment formed by 18 metal oxides sensors. Data from seven (LY2/LG, LY2/G, LY2/AA, LY2/Gh, LY2/gCTl, LY2/gCT, and P30/2) of 18 sensors were not included in the analysis, due to their low responses (response intensity lower than 0.05).

Results obtained with e-nose equipment corroborated the previous results obtained in the pyrazine analysis, which indicate the stronger roasted flavor of the patties made with the seasoning. In evaluated 11 sensors, patties with RWPS showed significantly higher response intensities than control (Figure 1). These observations agree with the results obtained by Gardner et al. [27], who also observed an increase in the sensor response with increasing roasting times in coffees. The highest differences were observed in sensors P30/1 and $\mathrm{PA} / 2$. Interestingly, this type of sensors has been previously linked to the roasted odor of different food products [27, 28]. Furthermore, P30/1 was also successfully applied to discriminate different coffees according to their roasting degree [29]. According to the higher sensor responses, the global area of the "odor profile," which can be considered as an index of the global odor intensity, was clearly higher (around 1.6 times) in the case of RWPS patties (Figure 2).

\subsection{Possible Mechanisms Explaining the Pyrazine-Promoting} Effect. The formation of pyrazines is governed by Maillardtype reactions that take place in processes at high temperatures. The main route of pyrazine formation is the condensation of Strecker aldehydes, which usually proceed from Strecker degradation. Chemically, the Strecker degradation is a decarboxylation of $\alpha$-dicarbonyls, which usually proceed from sugars [2], although new sources of $\alpha$-dicarbonyls 


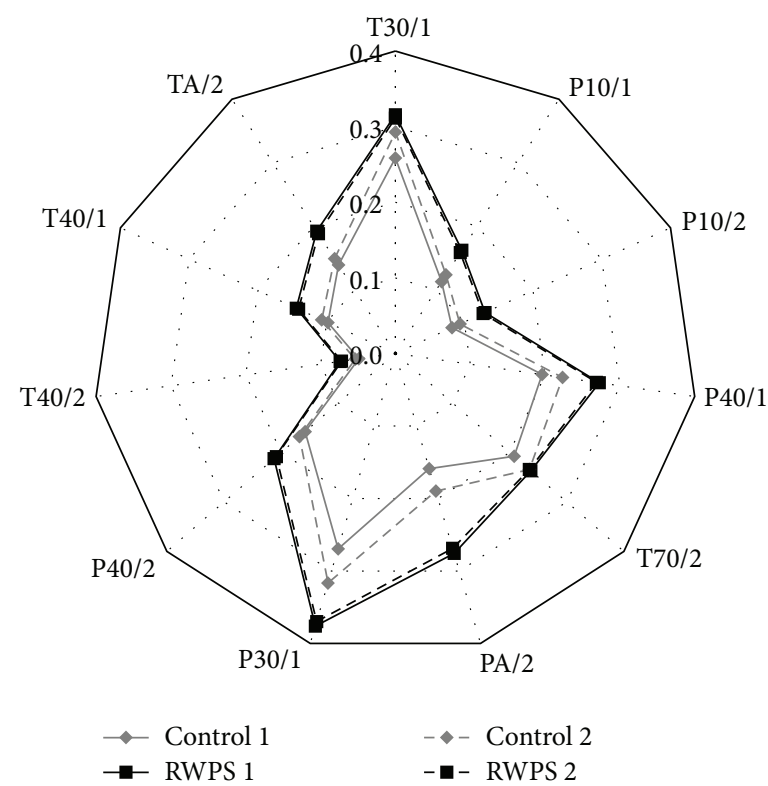

FIGURE 2: Odor profile of the two different batches of beef patties barbecued without (control) or with red wine pomace seasoning (RPWS), evaluated by the response intensity $\left(\left(R_{0}-R\right) / R_{0}\right)$ of 11 sensors from an $\alpha$-FOX electronic nose.

as quinones derived from polyphenols have recently been described [16]. Natural antioxidants, such as polyphenols, have been shown to promote Maillard-type reactions [15, 16], although previous studies also reported lower levels of pyrazines and roasted flavor in coffees with higher polyphenolic contents [13].

According to the seasoning composition and properties $[20,21]$ several factors, such as minerals, $\mathrm{pH}$ modifications, and polyphenol contents, could contribute to the pyrazinepromoting effect exerted by the seasoning. Among them, the polyphenol seems to be the main factor. Relatively slight modifications between the composition of control and RWPS patties were observed (data not shown). Ash content was similar in both types of patties, and no significant differences between metal levels were detected. The incorporation of RWPS reduced notably the values of $\mathrm{pH}$ (from 5.89 to 5.45); however stronger $\mathrm{pH}$ reductions (from 7 to 5) did not affect Maillard reaction [15]. The level of total polyphenols was the parameter most intensively modified by the seasoning incorporation. RWPS patties showed Folin index values around twice higher than control samples (data not showed). This difference was directly correlated to the high polyphenol content of RPWS $(24.4 \mathrm{mg} / \mathrm{g}$ expressed as gallic acid equivalents) [20]. Consequently, polyphenols are the most probable cause of the observed increase in the pyrazine levels of RWPS patties.

The capacity of polyphenols to promote the formation of $\alpha$-dicarbonyls derived from carbohydrates has been associated with their high capacity to reduce metals [15]. Interestingly, carbohydrates derived in $\alpha$-dicarbonyls only in model solution containing metals. This fact pointed out the role of metals in the propyrazine activity of polyphenols [15]. Extending this observation to patties, it is assumable that reduced metals, mainly iron, may cyclically participate in the Fenton reaction, generating hydroxyl radicals (Figure 3). These radicals are able to accelerate hexose degradation and continuously form $\alpha$-dicarbonyls, which participate in the Strecker degradation of amino acids and subsequently in the formation of pyrazines. This assumption is supported by the strong ferric reducing capacity showed by the seasoning (FRAP assay values of $275 \mu \mathrm{mol} \mathrm{Fe(II)/g} \mathrm{product)} \mathrm{[21].}$

In addition to the promoting effect on carbohydrate degradation, polyphenols, in their quinone state, can also participate in the Strecker degradation of amino acids. As a result, new Strecker aldehydes are formed, which may undergo further condensation (Figure 3 ) and contribute to the pyrazine formation [16].

Physical aspects of the matrix may also explain the high levels of pyrazines detected in samples with RWPS, since protein plays a key role in the release of volatiles from matrix to headspace [12]. RWPS was reported to interact with beef proteins [19], which may promote the release of volatiles from matrix to headspace. In this sense, RWPS could imitate the effect produced by salt that also enhances the release of volatiles from matrix [12].

\section{Conclusion}

The new seasoning enhanced the formation of pyrazines in the cooking process of beef patties. Although the mechanism and the specific agents responsible for the observed results remain unknown, it is possible to assert that RWPS is able to promote the formation of pyrazines, contributing to an adequate odor profile of patties and increase the intensity of the odor evaluated by electronic nose. Interestingly, the new seasoning may enable the use of less intense cooking conditions without affecting the "roast" flavor of the final product, using only natural additives. 


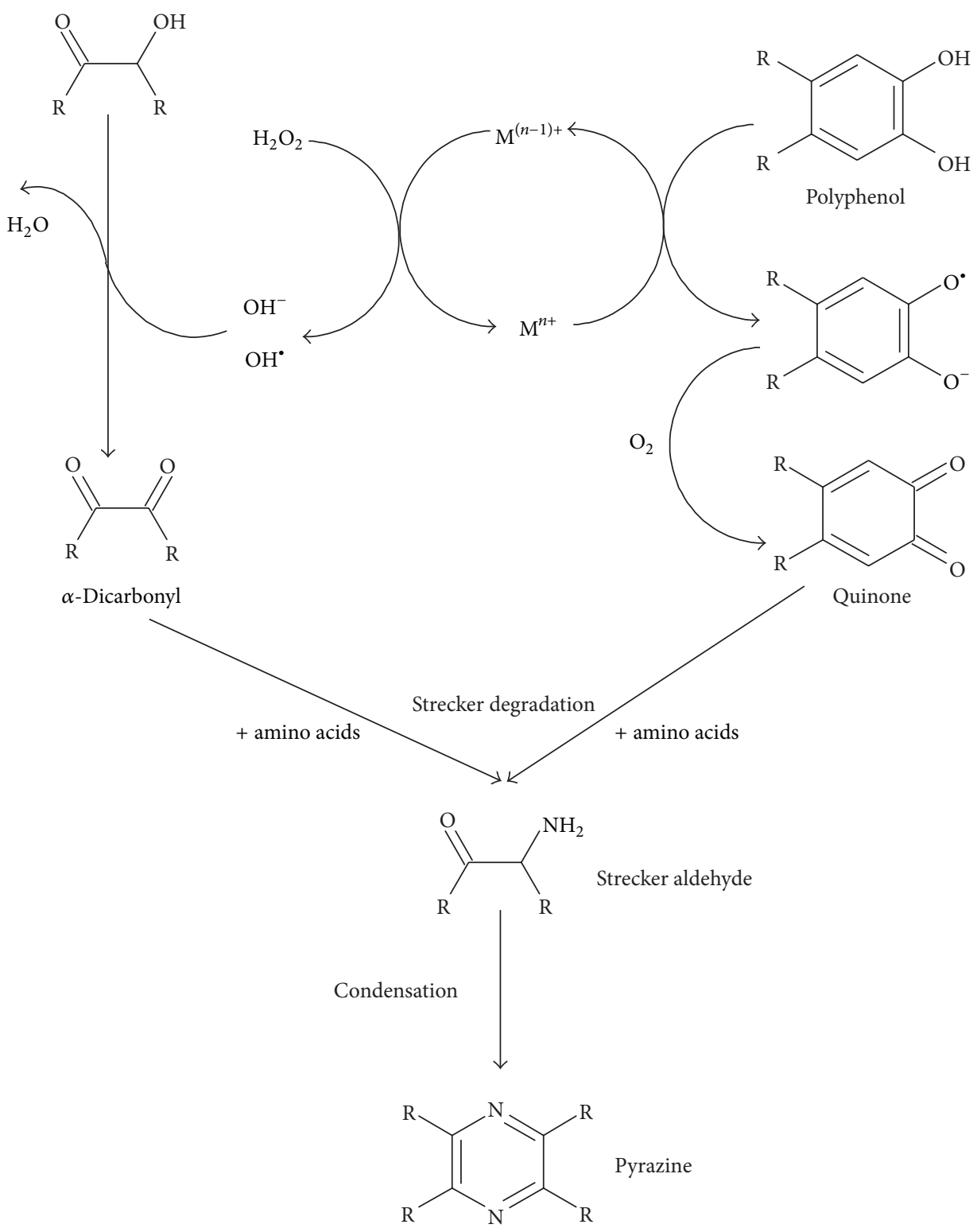

FIGURE 3: Reaction pathways proposed to explain the higher formation of pyrazines exerted by polyphenols of the studied seasoning. Adapted from $[2,15,16]$.

\section{Competing Interests}

The authors declare that there are no competing interests regarding the publication of this paper.

\section{Acknowledgments}

The authors are grateful for financial support from the Autonomous Government of Castilla y León through the research Projects BU282U13. The Ph.D. grants of Javier García-Lomillo and Raquel Del Pino-García (FPU grants) are funded by the Spanish "Ministerio de Educación, Cultura y Deporte."

\section{References}

[1] D. S. Mottram, "The effect of cooking conditions on the formation of volatile heterocyclic compounds in pork," Journal of the Science of Food and Agriculture, vol. 36, no. 5, pp. 377-382, 1985.

[2] R. Müller and S. Rappert, "Pyrazines: occurrence, formation and biodegradation," Applied Microbiology and Biotechnology, vol. 85, no. 5, pp. 1315-1320, 2010.

[3] EFSA, "Flavouring group evaluation 17, revision 1(FGE.17Rev1): pyrazine derivatives from chemical group 24. Opinion of the scientific panel on food additives, flavourings, processing aids and materials in contact with food (AFC)," The EFSA Journal, vol. 812, pp. 1-59, 2008. 
[4] D. D. Jayasena, D. U. Ahn, K. C. Nam, and C. Jo, "Factors affecting cooked chicken meat flavour: a review," World's Poultry Science Journal, vol. 69, no. 3, pp. 515-526, 2013.

[5] S. Mihara and H. Masuda, "Structure-odor relationships for disubstituted pyrazines," Journal of Agricultural and Food Chemistry, vol. 36, no. 6, pp. 1242-1247, 1988.

[6] Y. Zhang, X. Li, C.-K. Lo, and S.-T. Guo, "Characterization of the volatile substances and aroma components from traditional soypaste," Molecules, vol. 15, no. 5, pp. 3421-3427, 2010.

[7] J. C. Leffingwell, Flavor-Base, Leffingwell and Associates, Canton, Ga, USA, 2004.

[8] D. M. H. Farah, A. H. Zaibunnisa, and Misnawi, "Optimization of cocoa beans roasting process using response surface methodology based on concentration of pyrazine and acrylamide," International Food Research Journal, vol. 19, no. 4, pp. 1355-1359, 2012.

[9] M. Y. Jung, J. Y. Bock, S. O. Baik, J. H. Lee, and T. K. Lee, "Effects of roasting on pyrazine contents and oxidative stability of red pepper seed oil prior to its extraction," Journal of Agricultural and Food Chemistry, vol. 47, no. 4, pp. 1700-1704, 1999.

[10] S. Jiao, D. Zhu, Y. Deng, and Y. Zhao, "Effects of hot air-assisted radio frequency heating on quality and shelf-life of roasted peanuts," Food and Bioprocess Technology, vol. 9, no. 2, pp. 308319, 2016.

[11] A. Pasqualone, V. M. Paradiso, C. Summo, F. Caponio, and T. Gomes, "Influence of drying conditions on volatile compounds of pasta," Food and Bioprocess Technology, vol. 7, no. 3, pp. 719731, 2014.

[12] M. Pérez-Juan, M. Flores, and F. Toldrá, "Effect of pork meat proteins on the binding of volatile compounds," Food Chemistry, vol. 108, no. 4, pp. 1226-1233, 2008.

[13] S. J. Misnawi, B. Jamilah, and S. Nazamid, "Effect of polyphenol concentration on pyrazine formation during cocoa liquor roasting," Food Chemistry, vol. 85, no. 1, pp. 73-80, 2004.

[14] W. L. Porter, K. R. Conca, W. G. Yeomans, S. Diotte, A. Lynch, and J. Tate, "Modification of maillard browning in a microwaved glucose/glycine model system by water-soluble natural antioxidants and foods containing them," Journal of the American Oil Chemists' Society, vol. 83, no. 8, pp. 697-705, 2006.

[15] D. Wilker, A. B. Heinrich, and L. W. Kroh, "Model studies on the antioxidative effect of polyphenols in thermally treated dglucose/ 1-alanine solutions with added metal ions," Journal of Agricultural and Food Chemistry, vol. 63, no. 51, pp. 1097310979, 2015.

[16] G. P. Rizzi, "Formation of strecker aldehydes from polyphenolderived quinones and $\alpha$-amino acids in a nonenzymic model system," Journal of Agricultural and Food Chemistry, vol. 54, no. 5, pp. 1893-1897, 2006.

[17] A. D. Wilson and M. Baietto, "Applications and advances in electronic-nose technologies," Sensors, vol. 9, no. 7, pp. 50995148, 2009.

[18] J. S. Elmore, "Aroma," in Handbook of Muscle Foods Analysis, pp. 241-262, CRC Press, New York, NY, USA, 2008.

[19] J. Garcia-Lomillo, M. L. González-SanJosé, L. H. Skibsted, and S. Jongberg, "Effect of skin wine pomace and sulfite on protein oxidation in beef patties during high oxygen atmosphere storage," Food and Bioprocess Technology, vol. 9, no. 3, pp. 532542, 2016.

[20] J. García-Lomillo, M. L. González-SanJosé, R. Del Pino-García, M. D. Rivero-Pérez, and P. Muñiz-Rodríguez, "Antioxidant and antimicrobial properties of wine byproducts and their potential uses in the food industry," Journal of Agricultural and Food Chemistry, vol. 62, no. 52, pp. 12595-12602, 2014.

[21] R. Del Pino-García, J. García-Lomillo, M. D. Rivero-Pérez, M. L. González-Sanjosé, and P. Muñiz, "Adaptation and validation of QUick, easy, new, CHEap, and reproducible (QUENCHER) antioxidant capacity assays in model products obtained from residual wine pomace," Journal of Agricultural and Food Chemistry, vol. 63, no. 31, pp. 6922-6931, 2015.

[22] M. L. González San José, J. García Lomillo, R. Del Pino García et al., "Sazonador de origen vegetal con propiedades conservantes, sustitutivo de la sal, y procedimiento de obtención del mismo," ES2524870 B2, Spain, 2015.

[23] M. E. Corcuera Tecedor, Estudio de la aptitud de un aroma natural obtenido a partir de subproductos de buey de mar (Cancer pagurus) para su aplicación en distintas matrices alimentarias [Ph.D. thesis], Universidad de Burgos, Burgos, Spain, 2013.

[24] H. T. Lawless and H. Heymann, "Time-intensity methods," in Sensory Evaluation of Food, pp. 179-201, Springer, New York, NY, USA, 2010.

[25] M. S. Madruga, J. Stephen Elmore, A. T. Dodson, and D. S. Mottram, "Volatile flavour profile of goat meat extracted by three widely used techniques," Food Chemistry, vol. 115, no. 3, pp. 1081-1087, 2009.

[26] A. H. El-Ghorab, K. F. El-Massry, S. A. Shedied, M. S. Shaheen, F. Osman, and A. F. El-Hadaad, "Effect of water content chemical composition and antioxidant activity from volatile generated from beef fat in maillard reaction," Egyptian Journal of Chemistry, vol. 53, no. 3, pp. 367-383, 2010.

[27] J. W. Gardner, H. V. Shurmer, and T. T. Tan, "Application of an electronic nose to the discrimination of coffees," Sensors and Actuators B: Chemical, vol. 6, no. 1-3, pp. 71-75, 1992.

[28] Y. He, R. Hu, H. Zhang et al., "Characteristic aroma detection of coffee at different roasting degree based on electronic nose," Transactions of the Chinese Society of Agricultural Engineering, vol. 31, no. 18, pp. 247-255, 2015.

[29] T. Michishita, M. Akiyama, Y. Hirano, M. Ikeda, Y. Sagara, and T. Araki, "Gas chromatography/olfactometry and electronic nose analyses of retronasal aroma of espresso and correlation with sensory evaluation by an artificial neural network," Journal of Food Science, vol. 75, no. 9, pp. S477-S489, 2010. 

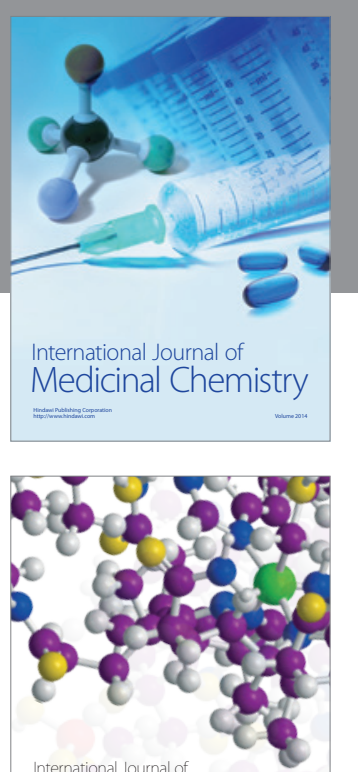

Carbohydrate Chemistry

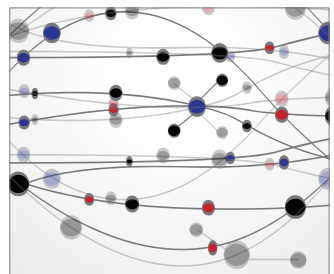

The Scientific World Journal
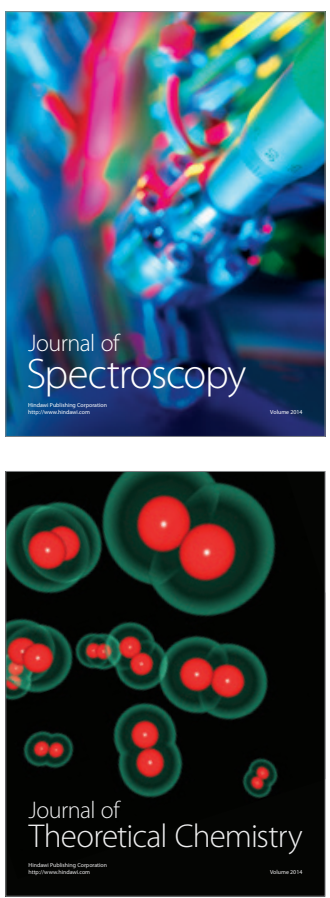
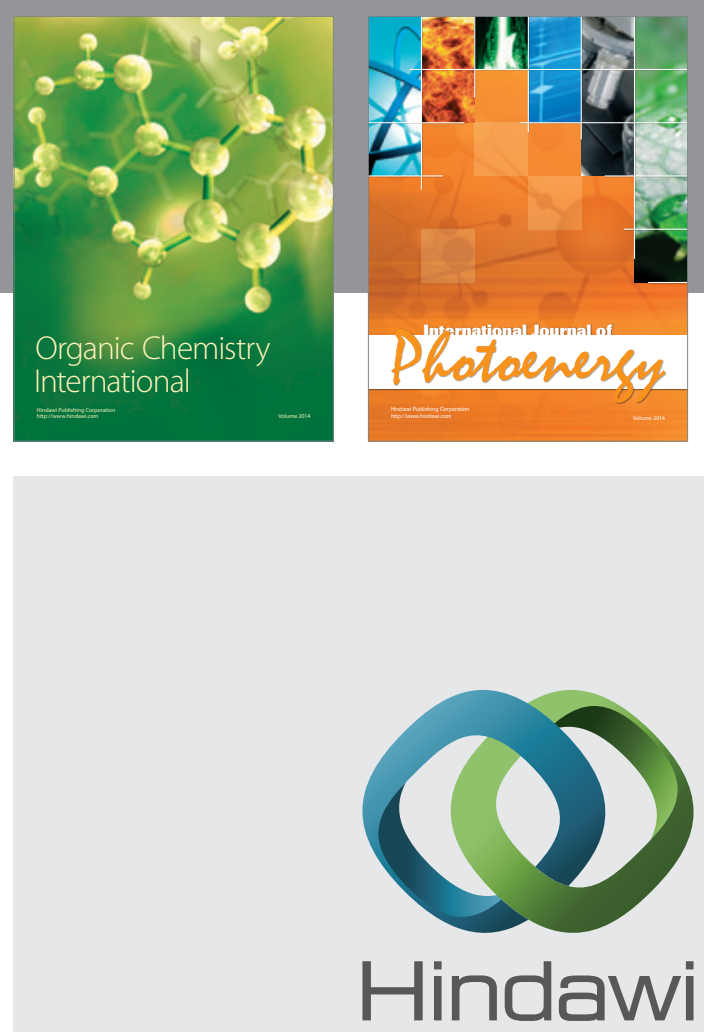

Submit your manuscripts at

http://www.hindawi.com

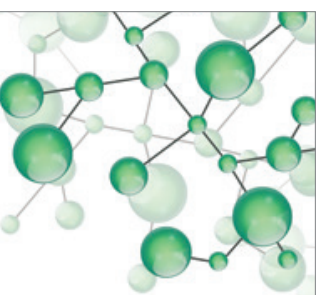

International Journal of

Inorganic Chemistry

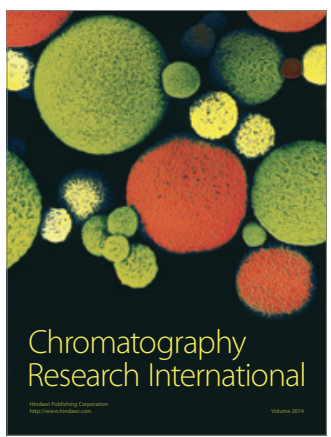

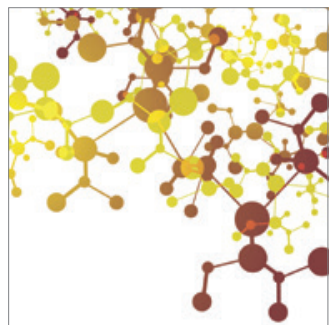

Applied Chemistry
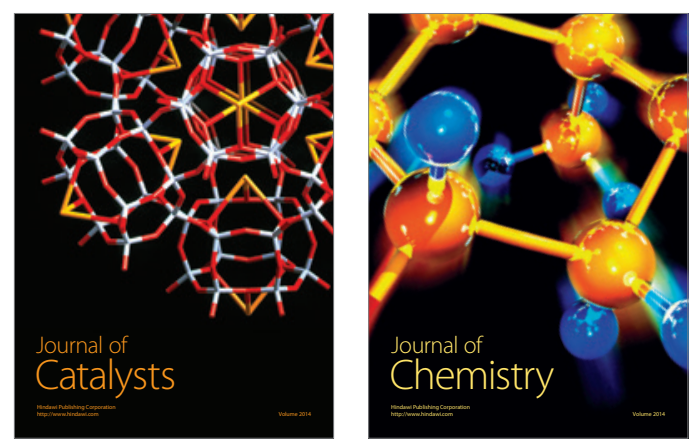
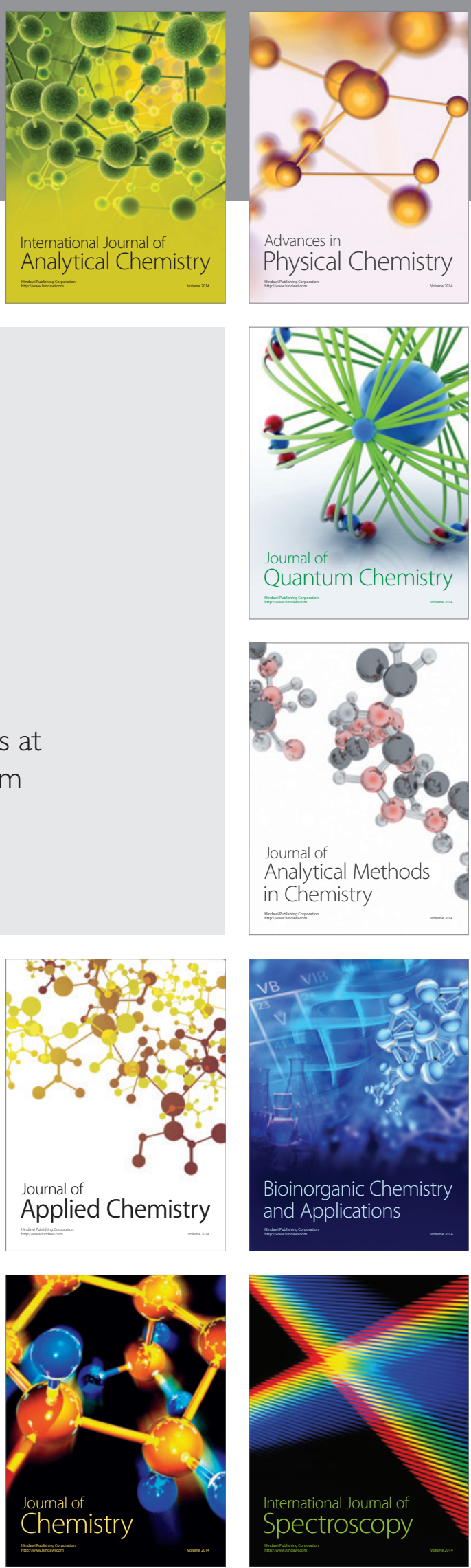